\title{
Kriteria vir die Kerklied
}

\author{
DJC VAN WYK
}

Tussen vernuwing en tradisie. So kan ons die spanningsveld waarin die kerklied leef, beskryf. Meermale kom in hierdie spanning ' $n$ wesenlike dubbelhartigheid by gelowiges aan die lig. Hulle hunker enersyds sterk na nuwe liedere, aangepas by en vertolkers van die nuwe, moderne tyd en sy lewensgevoel. Maar terselfdertyd wil hulle ou, bekende en maklike liedere bly sing. Wat ons die beste ken, het ons die liefste. Ons weerstaan verandering, maar soek dit terselfdertyd!

Maar die spanning tussen vernuwing en tradisie hoef nie noodwendig op dubbelhartigheid te dui nie. Dit moet ook nie noodwendig opgelos word nie. Die gelowige hét behoefte aan nuwe liedere om sy geloof uit te druk. God lê hom 'n nuwe lied in die mond. Maar van dieselfde God het hy groot skatte in die verlede ontvang wat hy wil bewaar. Is dit nie die wesenlike tekort in ons nuwe Afrikaanse psalmbundel nie? Die skatte uit die verlede is voortreflik bewaar. En daarby het dit ook hoofsaaklik gebly.

Maar die spanningsveld waarin die kerklied leef, strek nog wyer. Wat is die regte verhouding tussen die estetiese gehalte van die kerklied en die bevattingsvermoë van die gemeente? Immers, dit is nie slegs die teks of die melodie of die blote opname in ' $n$ bundel wat van ' $n$ lied 'n goeie kerklied maak nie. Daar moet iets bykom voordat van "kerklied" sprake kan wees: die gemeente. Ons sou ten alle tye, esteties gesproke, ' $n$ beter kerklied kon saamstel as ons die gemeente kon vergeet. Die kerklied mag nooit losgemaak word van die kerklike gemeenskap nie. Daar moet rekening gehou word met wat die gemeente liefhet en kan sing. En daar moet ook met estetiese oorwegings gereken word. Want wat geliefd is by die gemeente is nog nie om dié rede alleen goed genoeg nie. "De geschiedenis van het kerkelijk en geestelijk lied is een geschiedenis met goede en met kwalijke kanten. Wakkere liederen, die de bevrijding van Godswege proclameerden en deze konden begeleiden en versterken, zijn er gezongen, evengoed als liederen van berusting die de gemeente zand in de ogen strooiden. En de laatsgenoemden konden bij tijden de meeste geliefde zijn" (1: p. 97).

Maar Calvyn se hoë ideaal van indrukwekkende verhewenheid, van gewig en majesteit vir die kerklied moet ook nooit verwar word met onnatuurlike swaarwigtigheid nie. Die kerklied moet gesing kan word. Maar dit moet ook gewig hê. So gebeur dit dat die estetiese eise in konflik kan kom met die pastorale tegemoetkoming aan wat die gemeente nodig het en aanspreek. 
'n Volgende spanningsveld waarin die kerklied voortdurend leef, is die verhouding waarin dit staan tot die kultuur van sy tyd. Elke liedboek weerspieël iets van die gees van sy tyd. 'n Kerklied mag nie totaal vreemd wees in sy eie tyd nie. Dit kan ten opsigte van ons Afrikaanse psalm- en gesangboek 'n baie kritiese vraag word. Hoeveel weerspieël hierdie boek van die worsteling van gelowiges om tot helder en sterk lofprysing van God te kom, hier en nou in Afrika, te midde van verstedeliking en sekularisasie? Ondanks die proses van verstedeliking sing ons nog oorwegend liedere gebaseer op 'n plattelandse gemeenskap. Ons moet meer liedere vind wat oor die geloof en oor God spreek in die taal van die moderne, gesekulariseerde, tegnologiese gemeenskap.

Maar dit moet met groot behoedsaamheid gedoen word. Spesifieke verwysings na bv. wetenskaplike ontdekkings wat vandag baie eietyds kan wees, is môre verouderd. 'n Goeie kerklied moet soveel kwaliteit hê dat dit nie so maklik verouder nie. Die werklike groot kerklied bly relevant.

Die kerklied is nie ' $n$ vreemdeling in die kulturele lewe van sy eie tyd nie, maar lewer hom ook nooit totaal uit aan die kenmerkende veranderde lewensbesef van elke tyd nie. Ons moet wegkom van die treffersparade-mentaliteit af. Vandag is dié kerklied goed, môre weer ' $n$ ander. Ons moet in die kerk uit wees op duursaamheid, dit wat karakter het. Die goeie kerklied het ' $n$ ingeboude distansie tot die kulturele lewe van sy eie tyd.

Die spanningsveld waarin die kerklied, net soos die evangelie en ander liturgiese elemente self ook, in die Swart kerke in Afrika leef, spreek duidelik uit die woorde van kardinaal Malula, aartsbiskop van Kinshasa: Voorheen het die sendelinge Afrika gekersten. Nou moet die Christene van Afrika die Christendom Afrikaniseer. Die kerk in Afrika moet leer om getrou te wees aan die Woord van God, nie aan die kultuur van die sendeling wat aan hom die evangelie gebring het nie. Eers as die kerk ten volle inheems is, kan hy werklik getrou wees aan Jesus Christus en relevant in die samelewing. Ongelukkig is daar steeds Swart Christene vir wie die kerkgebou en die kerklied eers status kry as dit Westers is. Daarom word so graag liedere uit die Engelse kerkwêreld gesing.

Die vraag na kriteria vir die kerklied stel die kerk en elke gelowige of kommissie wat aan 'n nuwe liedboek begin werk, voor bykans onoorkomelike vrae en probleme, veral wat die musikale aspek van sodanige kriteria betref. Daároor vind ons immers in die Skrif geen direkte aanduidinge nie. Daar kan hoogstens enkele afleidings gemaak word. Dit is waarom die Nederlanders met hulle Liedboek vir die Kerke maar op die ou end met 'n algemene aanduiding volstaan het: om vir die gemeente gesonde, stylvolle melodieë aan te bied wat goed singbaar is en die teks dra. 
Wat die woordinhoud van die kerklied betref, is die saak natuurlik baie makliker. Dié inhoud is reeds in die Skrif gegee. Omdat daar steeds woelinge rondom die nuwe Afrikaanse psalm- en gesangboek voorkom, en omdat ' $n$ nuwe beryming van die psalms steeds in die weer is, is dit tog sinvol om ook oor die woordinhoud van die kerklied te bly besin. Daaroor kortliks die volgende opmerkings.

Inhoudelik moet die kerklied Skriftuurlik wees. Dit moet gerig wees op die eer van God. In sy lied dink die kerk in die eerste plek aan die groot dade van God. Daarom sal die goeie kerklied altyd 'n sterk objektiewe karakter hê. Dit bly steeds 'n wesensonderskeid: die Reformatoriese kerklied is, getuigend en belydend, gerig op die werk en die Woord van God. Die piëtistiese kerklied is ek-gerig, gerig op die eie geloofsbelewing. Maar die objektiwiteit van die kerklied mag nooit verabsoluteer word asof daar nie ook wel 'n subjektiewe element aanwesig is nie. Dit gaan in die kerklied immers ook om die heil van die mense. Daarom moet dit ook wat sy woordinhoud betref, vir die gemeente begryplik wees. Die hinderlike oorspanning van die subjektiewe element in die kerklied kan voorkom word as die persoon van die enkeling slegs herkenbaar word binne die breër verband van die gemeente.

Verder moet die berymde kerklied die toets van literêre kritiek kan deurstaan. Die teks van die kerklied bevat nie maar 'n klomp rymelary nie. Dit is sterk, oordinkte, geloofsgeïnspireerde, digterlik-eenvoudige geloofsuitinge.

Paulus se bekende uitspraak in Kol. 3 onderstreep belangrike sake in verband met die inhoud van die kerklied. Hy plaas sy uitspraak oor sang in die middel van 'n reeks uitsprake oor liefde, vergewing, vrede, dankbaarheid. Die boodskap van Christus moet in sy volle rykdom in die gelowiges bly. Wys toiingrige kerksang op die feit dat die boodskap van Christus nie só in ons woon nie? Is dit waar die gemis aan liefde, vrede, vergewing en dankbaarheid vandaan kom? "Should one of the qualifications for church musicians (choirs, choir directors, organists, soloists) be a thankful spirit? What would an attitude of grace and gratitude do for the music problems in our church?" (2: p. 21). Daar is 'n tweërlei inspirasie nodig om in die kerk te sing: die vervulling met die Heilige Gees en die ryk inwoning van die Woord van Christus in die hart.

Vra ons na musikale kriteria vir die kerklied, word die saak baie moeilik. Waarom beskou ons sommige melodieë as onwaardig, eenvoudig net nie geskik om in ons kerkboek opgeneem te word nie? Ons moet erken dat die kerklied uit die tyd van die Reformasie, wat die struktuur van die melodie en die verhouding van woord en toon betref, so 'n diepgrypende invloed uitgeoefen het op ons bewuste en onbewuste norm van wat ' $n$ kerklied is, dat sekere liedere daarvolgens net nie toegelaat kan word nie. "Het blijkt hoe moeilijk het is, 
ons standpunt daarin zo helder bewust te maken dat het voor anderen ook geldigheid heeft. Het is wel duidelijk dat ons standpunt samenhangt met de geschiedenis van ons kerklied in onze Protestantse Westerse Kerk". (3: p. 59). Daaroor later meer.

Hier tree die spanning weer in. Ons wil graag bly by wat ons liefhet uit die 16e eeu. Maar moet moderne tekse nie deur moderne melodieë gedra word nie? En die moderne musiekstyl is totaal vreemd aan wat ons liefhet uit die 16e eeu. Moderne musici kan beswaarlik nog melodieë skryf met dieselfde melodiese, ritmiese en tonale gegewens van vroeër.

Die Raad vir Kerkmusiek van die Ned. Hervormde Kerk het ook as deel van 'n rapport oor die troumars, 'n poging aangewend om tot ' $n$ kort formulering van kriteria vir die kerkmusiek in die algemeen en die melodie van die kerklied in die besonder te kom. Dit lui, effens verkort, soos volg:

"Die kerkmusiek is vir die kerk, dus vir die lidmate van die kerk, en juis daarom sal dit groepsgebonde wees. Vir verskillende volkere in dieselfde tyd mag daar ander kriteria geld. Dit word bepaal deur kultuur en kultuur- en kerkhistoriese agtergronde. Die kerk en die kerklied neem kennis van die kultuur van sy tyd, maar gaan nie absoluut daarin op nie. Dit hou rekening met kerkhistoriese agtergronde. Die voorskriftelike en gebruike sal van groep tot groep verskil. 'n Swart volk kan bv. ander kriteria hê vir hulle kerkmusiek as 'n blanke volksgroep. ' $n$ Mens sal dus nie binne 'n bepaalde kerkkultuur ander kriteria probeer vaslê as wat op daardie stadium vir die bepaalde groep geldend mag wees nie.

\section{- SODANIGE KRITERIA IS TYDGEBONDE}

Kriteria wat geldend was in vorige tye, hoef nie noodwendig bv. met die kriteria vir die 20 ste eeu ooreen te stem nie. Op 'n stadium in die geskiedenis was die kriterium in elk geval - geen musiek in die kerk. Dit kan selfs binne 'n dekade verskil. Neem maar as voorbeeld die sing van sommige gesangewysies in die Hervormde Kerk, wat enkele jare gelede haas ondenkbaar was. Nou word dit lustig gesing. 'n Stuk musiek kan ook mettertyd ingeburger raak as kerkmusiek. Dink maar aan vroeëre volkswysies wat vandag psalm- en gesangmelodieë is, bv. Ges. 217.

\section{- SODANIGE KRITERIA HET 'N SUBJEKTIEWE ELEMENT}

Individuele subjektiewe gevoel behoort nie ' $n$ rol te speel nie. Daar is egter wel ' $n$ stemmingsgebondenheid. Die "atmosfeer" onder ' $n$ bepaalde omstandigheid of die stemming van 'n bepaalde groep sal invloed hê. Bepaalde gebeure in die erediens sal die groep se subjektiewe behoeftes en oordele verder beïnvloed. Dit word in ' $n$ rigting gestuur deur die teologiese en kerkhisto- 
riese agtergronde. Daar is dus 'n subjektiewe element wat gebonde is aan die groep, die gebeure en die tyd.

\section{- MET INAGNEMING VAN BOGENOEMDE DIE VOLGENDE:}

i. Die belangrikste kerkmusiek is seker dié musiek wat die woorde van die gemeente ondersteunend dra in die kerklied.

ii. Die Skrif en die kerkmusiek. Die Skrif is slegs voorskriftelik wat die gedagte-inhoud en die gees van die kerklied betref. Die Skrif sê in indirekte sin ook iets oor die stemming. In Eks. 15:21, 11 Kron. 16:9, Ps. 13:6; 104:33, Jer. 20:13 word opgeroep om tot eer van die Here te sing. In Hand. 16:25 verneem ons dat die gemeente lofliedere tot eer van God gesing het. En in Kol. 3:16 word gesê: "Sing in julle hart met dankbaarheid", wat seker ook van die uitdruklike sang gesê kan word.

Op verskeie plekke in die Bybel verneem ons egter ook van Klaagliedere (2 Sam. 1:17, 2 Kron. 25:25, Jer. 9:20, Eseg. 32:16, Amos 5:1, Miga 2:9, Matt. 11:17, Luk. 7:32 en ander plekke).

Verder moet kerkmusiek ondersteunend wees aan die Woord. Dit is ondersteunend aan die Woord deur die inhoud van die lied as antwoord van die gemeente te bevestig. Die stemming en "emosie" (wat die Woord as antwoord vra) wat deur die musiek ondersteunend gedra word, bevestig die antwoord.

iii. Wat voor en na die erediens gespeel word, maak nie deel uit van die liturgie van die kerk nie. Dit beteken egter nie dat hierdie musiek 'n willekeurige saak is nie. Wat tydens die liturgiese handeling gaan gebeur of gebeur het, het besliste seggenskap oor wat daar rondom gebeur.

iv. Wie die komponis is of wat die oorsprong van 'n sekere stuk musiek is, hoef nie te hinder nie. Wanneer daar egter assosiasie-hindernisse is wat die horisontale en/of vertikale handeling vertroebel, dan is die oorsprong belangrik.

v. Ritme en melodie. Ritme op sigself kan nie ' $n$ melodie diskwalifiseer nie. Die interpretasie (vertolking) is baie belangrik en 'n verkeerde interpretasie (vertolking) of assosiasie kan diskwalifiserend werk. Dit kan verkeerde tempo, pousering of frasering wees.

Die melodie en sy vertolking moet bevestiging van die gees en inhoud van die kerklied bly, hetsy as antwoord van die gemeente of in sy verkondigingskarakter.

vi. Dit is veral vir die lidmate van die kerk van belang waarmee die musiek geassosieer word. Indien assosiasie die kerk nie hinder nie, is die oorsprong van die musiek nie meer belangrik nie. 
vii. Wat die kerklied as sodanig betref, is die singbaarheid daarvan noodsaaklik. Dit sou niks baat indien dit aan alle ander kriteria voldoen maar dit is nie singbaar nie.

viii. Kerkmusiek moet waardig wees. Wanneer daar van waardigheid sprake is, bedoel ons dat dit aan al bg. kriteria-vereistes voldoen." Tot sover die Raad vir Kerkmusiek.

J.J.A. van der Walt van Potchefstroom het ook in sy werk oor die Afrikaanse psalmmelodieë bepaalde musikale kriteria vir die kerklied probeer vaslê. Hy doen dit veral in aansluiting by Calvyn. Van der Walt lê 'n paar riglyne neer wat nie sonder meer geïgnoreer kan word nie. Dit sal goed wees om van dié riglyne kennis te neem, juis nou dat daar hernude, verbete aandrang is om meer populêre, maklik-singbare en oppervlakkige kerkliedere te aanvaar.

Van der Walt sê dat Calvyn se sobere gebruik van musiek nie op onkunde of antipatie berus het nie maar juis op 'n intieme kennis van die oorsprong en buitengewone krag van musiek en van die verdorwenheid van die mens. Die eis om woordhelderheid is op sy konsekwentste in die Geneefse musiek deurgevoer. Daar is afgesien van meerstemmigheid en in eenvoudige, objektiewe, sillabiese melodieë is getrag om, met behoud van die oortuigingskrag van die musiek, die groots moontlike woordhelderheid en -begrip te bevorder. Daar is in die Geneefse kerklied 'n krag en bewoënheid wat elders gemis word. Hierteenoor staan die oppervlakkigheid, subjektivisme, humanisties-geörienteerde musiek van die $19 \mathrm{e}$ eeu - met eintlik geen ander deug as dat dit maklik, lekker singbaar is nie.

Van der Walt probeer om die musikale norme wat aan die melodie gestel kan word soos volg saam te vat:

- Die melodie moet daartoe dien om die gelowige se hart te laat ontvlam om God met 'n kragtiger en gloeiender ywer aan te roep. Dit beteken dat die artistieke gehalte van die melodie onberispelik moet wees, anders sal dit nie egte ontroering kan bewerkstellig nie.

- Die melodie moet dien om die woorde in die hart in te lei soos 'n tregter die wyn in ' $n$ vat inlei. Dit beteken daar moet ' $n$ innige band wees tussen die teks en die musiek.

- Daar moet uit die hart gesing word maar die hart vereis die verstand. Dit beteken daar moet woordhelderheid wees in die samestelling van teks en musiek.

Van der Walt stel 'n paar basiese eise waarvolgens hy die artistieke kwaliteit van die kerklied wil beoordeel. Musiek, sê hy, is geordende toonmateriaal. Dié ordening is moontlik op grond daarvan dat die mens die tone kan waarneem as ' $n$ verskeidenheid, as 'n eenheid en 
as ' $n$ verskeidenheid in die eenheid. Die eenheid en verskeidenheid bestaan ten opsigte van die vier basiese eienskappe van klank nl. toonhoogte, toonduur, toonsterkte en toonkleur. Hoë tone en groepe tone veroorsaak spanning; lae tone en groepe tone veroorsaak ontspanning.

Van der Walt se hartstog en ywer vir die Geneefse kerklied is bekroon met ' $n$ ryke opname en herstel van die Geneefse melodieë in die Afrikaanse psalmbundel van 1978.

Samevattend wil ons sê dat die melodie van die kerklied 'n karaktervolle, spanningvolle samehang vorm van tone wat op die teks afgestem is en dit ondersteun. Wanneer teks en melodie so tot ' $n$ eenheid saamgevoeg is, is dit so sterk dat dit vra om herhaal te word, keer op keer, strofe vir strofe. Teks en melodie kan, afsonderlik en gesamentlik, geheime bewaar wat hulle nie sommer meteens prysgee nie. Daarom moet daar aan die kerklied gewerk word. Lekker-sing mag nie die enigste eis wees nie! Intussen bly die een kerklied vir sommige ' $n$ wonder. Ander het daarin 'n afkeur. "Bij ons een verwarrende chaos, bij God volvoering van zijn plan", (1: p. 15).

Daarom ook is die skepping van 'n kerklied nié maar ' $n$ interressante stokperdjie nie. Dit kan ook nie binne 'n bepaalde tydsbestek afgejaag word nie. "To write a hymn is to do more than use correctly certain techniques. It is to look on the face of God, to worship in His presence, embrace his will, accept his cross and live daily under its obedience ... True hymn writers have not primarily sought to write hymns but to know God; and knowing him, they could not but sing. Their are the hymns that have lived through the ages and will live into the future. We need this kind of hymn writing today if our generation will contribute anything real to the churches treasury of worship and praise". (4: p. 23).

Ten slotte enkele opmerkings oor die kerklied onder Swart Christene in Afrika.

Ook op hierdie terrein is die proses en poging om die Christelike geloof te Afrikaniseer aan die gang. Soos 'n teoloog uit Afrika dit onlangs gestel het: die kerklied, soos die evangelie en die res van die liturgiese vorme moet eindelik die stempel kan dra van: "made in Africa". Daar word gesoek na die kerklied in Afrika-idioom. Vanaf die vroegste tye in die Sendinggeskiedenis in Afrika was die vraag brandend: wat moet diegene wat tot bekering kom, in die kerk sing? Al was daar oor die afgelope vyftig jaar heelwat vordering, bly dit steeds so dat in die meeste kerke in Afrika oorwegend liedere met ' $n$ Europese herkoms gesing word. Swart Christene dra self die meeste skuld daarvoor. Hulle gee dikwels voorkeur aan die lied met 'n Europese herkoms omdat dit as van hoër gehalte beskou word. Die Westerse meerderwaardigheid het diep ingedring. Alleen Westerse 
musiek, ook kerkmusiek is werklik musiek. Die musiek van Afrika is "primitief". So word meermale ten onregte gemeen.

Die probleem van kriteria vir die kerklied verdiep as ons van die Westerse kerke na die Swart Kerke gaan. Dit blyk baie gou dat daar nie algemeen-geldende kriteria vir die kerklied onder alle volke en in alle kerke kan wees nie. Die Geneefse psalmmelodieë is wesensvreemd aan die aard en musikale aanleg van die Swartman. Hy sing dit eenvoudig nie.

Selfs heel oppervlakkige waarneming bring die volgende kenmerke van die sang in swart kerke aan die lig.

- Dit is besonder hartlik, spontaan. Daar word met egte oorgawe gesing.

- Die sang geskied sonder enige begeleiding. Die orrel is 'n vreemde instrument.

- Die sang is geweldig ritmies. Veral die prosessieliedere by kerkinwydings gaan gepaard met handgeklap, ligte dansbewegings en voetgestamp.

- Vir ons Westerse gevoel maak die sang soms 'n geweldige eentonige indruk. Herhaling van dieselfde refrein kom soms eindeloos voor.

- Die liedere is baie eenvoudig. Dit word maklik meerstemmig gesing. Daar is volop geleentheid vir improvisasie.

- Die vraag oor die herkoms van die melodie, die komponis of hoeveel bygeloof en heidendom in die agtergrond van 'n lied skuil, kom nie in die gesigsveld nie.

Die Westerse kerklied is vreemd aan Afrika. Die Swartman het min begrip en liefde vir die verskuns. Sy geliefde vorm is veel eerder'n vry resitatief, gesing deur een persoon, gewoonlik die leier, gevolg deur ' $n$ kort koorgedeelte, gesing deur' $n$ koor of die gemeente. Die Europese kerklied is lief vir toevallige verhogings - of verlagingstekens wat die Swartman nie kan sing nie. Netso vreemd is die gebruik van melismata. Melodieë met Europese herkoms pas ook nie goed by die Woorde van Afrikatale nie. ' $n$ Stygende lyn in die melodie kan, gepaard met 'n dalende lyn in die woordaksent, verwarrende betekenis tot gevolg hê. Woorde van Afrikatale kan nie in melodieë wat vir tale met totaal ander ritme - en aksentkwaliteite geskep is, in forseer word nie.

Dit is duidelik: die Swart kerke sal moet toesien dat daar vir hulle deur hul eie gelowige musici oorspronklike kerkliedere geskep word; liedere in egte Afrikastyl. "The future, in fact, lies definitely with African Christian musicians themselves. It is they who must provide the hymnody of the future, for in African music with its unfamiliar melodic and especially rhythmic subtlety, the European musician is quite out of his depth". (5: p. 57). 
Daar is gepoog om in hierdie artikel enkele van die gedagtes en riglyne oor kriteria vir die kerklied saam te vat.

Die kern van die saak bly: Christene sing omdat God waardig is om geprys te word. Die werk om vir dié doel die beste lied onder alle volke te vind, gaan voort. Dit sal, in die woorde van WF Dankbaar voortduur tot die einde: Elke liedboek is onvolmaak en moet na verloop van tyd hersien word. Soos wat die kerk die onuitputlike rykdom van die Bybel telkens op 'n nuwe wyse sal verwerk in die teologie en prediking, so sal die kerk hierdie rykdom telkens in nuwe liedere besing. Die volmaakte lied, die nuwe lied wat sy gelyke nie ken nie, word - om 'n Bybelse beeld te gebruik (Openb. 5:9) - alleen in die hemel gesing. En daar is geen liedboek meer nodig nie.

\section{Verwysings}

1. Honders, AC. En wat zij zong hoorde ik dat psalmen waren, in Klinkend Geloof, onder redaksie van AC Honders. 's-Gravenhage, Boekencentrum, 1978, p. 9-15, 97-103.

2. Huizenga, Nolan C. A Biblical "tune-up" for hymn singing. Christianity Today, vol. XXIV, no. 12, June 27,1980 , p. 20-21.

3. Schuurman, Adr. C. De muzikale arbeid aan het nieuwe Liedboek voor de kerken, in Uit de werkplaats van het Liedboek, deur AW Lazonder e.a. 's-Gravenhage, Boekencentrum, 1974, p. 52-64.

4. Clarkson, Margaret $M$. What makes a hymn good? Christianity Today, vol. XXIV, no. 12, June 27, 1980, p. 22-23.

5. Jones, AM. African Hymnody in Christian Worship. Gwelo, Mambo Press

\section{Bibliografie}

1. Dinwidie, Richard D. Hymns for Today: Modern Metaphors for Worship. Christianity Today, vol. XXV, no. 18, October 23, 1981, p. 30-31.

2. Fasholé - Luke, Edward W. Footpaths and Signposts to African Christian Theologies. Scottish Journal of Theology, vol. 34, no. 5, 1981, p. 385-414.

3. Friesen, Albert WD. A Methodology in the Development of Indigenous Hymnody. Missiology, vol. 10, no. 1, January 1982, p. 83-96.

4. Kunst, PG. Kerkzang in de Nederlanden. Kok, Kampen, 1981.

5. Routley, Eric. Church Music and the Christian Faith. London, Collins Liturgical Publications, 1980.

6. Van der Walt, JJA. Die Afrikaanse Psalmmelodieë. Potchefstroom, Pro Rege, 1962. 